\title{
Critical Effects of Smoking Parameters on the Levels of Polycyclic Aromatic Hydrocarbons in Traditionally Smoked Fish and Meat Products in Finland
}

\author{
Mirja Hokkanen (iD, ${ }^{1}$ Ulla Luhtasela, ${ }^{2}$ Pirkko Kostamo, ${ }^{2}$ Tiina Ritvanen, \\ Kimmo Peltonen, ${ }^{1}$ and Marika Jestoi ${ }^{2}$ \\ ${ }^{1}$ Finnish Food Safety Authority Evira, Research and Laboratory Services Department, Helsinki FI-00790, Finland \\ ${ }^{2}$ Finnish Food Safety Authority Evira, Food Safety Department, Helsinki FI-00790, Finland \\ Correspondence should be addressed to Mirja Hokkanen; mirja.hokkanen@evira.fi
}

Received 8 June 2018; Revised 7 August 2018; Accepted 3 September 2018; Published 10 October 2018

Guest Editor: Alberto Fiore

Copyright (c) 2018 Mirja Hokkanen et al. This is an open access article distributed under the Creative Commons Attribution License, which permits unrestricted use, distribution, and reproduction in any medium, provided the original work is properly cited.

\begin{abstract}
Eighty fish products and 62 meat products were sampled and analysed in Finland, in the year of 2012 for four marker polycyclic aromatic hydrocarbons (PAH4) with an accredited gas chromatography-tandem mass spectrometry method. In general, the determined PAH4 levels were relatively low and below the maximum levels. The mean concentrations of smoked fish samples were $0.7 \mu \mathrm{g} \cdot \mathrm{kg}^{-1}$ for benzo[a] pyrene and $3.9 \mu \mathrm{g} \cdot \mathrm{kg}^{-1}$ for the PAH4 sum, whereas in smoked meat samples, mean benzo[a]pyrene and PAH4 sum levels were $2.2 \mu \mathrm{g} \cdot \mathrm{kg}^{-1}$ and $11 \mu \mathrm{g} \cdot \mathrm{kg}^{-1}$, respectively. However, PAH4 sum concentrations ranged from not detected to $200 \mu \mathrm{g} \cdot \mathrm{kg}^{-1}$ particularly among meat products, underlining the importance of controlling the smoking process. In this study, the effect of selected smoking parameters, i.e., smoking technique (direct/indirect), smoking time (less than five hours/more than five hours), smoke generation temperature (optimised/nonoptimised), and the distance (less than five metres/more than five metres) between the food and the smoke source, confirmed the linkage between the smoking factors and the PAH4 levels formed in fish and meat products. As guidance for a safe smoking process, it was demonstrated that an indirect smoking technique, a shorter smoking time, an optimised smoke generation temperature, and a longer distance from the smoke source generated lower PAH concentrations in food products. However, while a shorter smoking time generated lower PAH levels in meat products, the levels in fish products were unexpectedly higher than in those smoked for a longer time. Other factors, such as the smoking type (cold smoking/warm or hot smoking) and the fish size, may have affected this result.
\end{abstract}

\section{Introduction}

Polycyclic aromatic hydrocarbons (PAHs) consist of a versatile group of organic compounds that have at least two or more aromatic rings joint together $[1,2]$. They are fat soluble and chemically stable compounds that are classified as human carcinogens [1]. Several metabolic pathways may result in reactive intermediates inducing mutagenic or carcinogenic processes of PAHs [3]. The carcinogenic capacity varies between them, despite having similar structural properties [4]. Those with four to six fused rings, such as benzo $[a]$ pyrene $(\mathrm{BaP})$, are effective carcinogens belonging to Group 1 carcinogens according to the International Agency for Research on Cancer (IARC) [5]. Additionally, PAHs have teratogenic, haematological, and immunotoxic effects, and their concentrations in food should therefore be as low as reasonably achievable (ALARA principle) [6-8].

PAHs are formed during the incomplete combustion of organic matter, and they are widely distributed in the environment via air $[6,7]$. Industry, traffic, smoking, forest fires, and volcanic eruptions generate PAHs, and humans are consequently mainly exposed by inhalation, skin contact, and ingestion [6,7]. Despite also being environmental contaminants, PAHs are formed in food processing, such as drying, grilling, roasting, and smoking $[6,7,9]$. For nonsmokers, the diet appears to be the main source of PAH exposure $[9,10]$.

Food smoking is one of the oldest preservation methods and is still widely used [11-14]. However, smoking is 
nowadays mainly used to obtain the desired colour, flavour, aroma, and appearance in the smoked food rather than for preservation purposes $[14,15]$. Traditional smoking is generally performed by the formation of smoke from wood $[16,17]$. Smoke is defined as the result of thermal pyrolysis of wood when access to oxygen is limited [6]. PAHs and other chemical compounds occur in smoke particles, which can migrate into the food product being smoked [2, 18]. Wood smoke contains a combination of antioxidant and antimicrobial chemicals (e.g., phenols, carboxylic acids, aldehydes, and acetic acids), but also some harmful compounds, such as PAHs [12, 17, 19]. PAHs are potential health hazards associated with smoked foods, in which they typically occur as a complex mixture $[6,13]$. In Finland, smoking with direct and indirect techniques is widely used in the processing of meat and fish products. For direct smoking, smoke is generated from an open fire in the same chamber as the smoked product, whereas in indirect smoking, the smoke is generated in an external chamber separated from the food and the smoke is led to the product from the external smoke generator $[16,20]$. Alongside the smoking technique, the type of process (grilling, roasting, smoking, and drying), the distance between the food and the smoke source, the process time, and temperature impact the formed PAH levels [6].

Commission Regulation (EC) No. 1881/2006 specifies the maximum levels (MLs) of BaP in different foodstuffs [21]. In 2008, the European Food Safety Authority (EFSA) concluded that $\mathrm{BaP}$ alone is not a suitable indicator for the occurrence and toxicity of PAHs in foods [3]. Therefore, additional MLs for the sum of four PAHs (PAH4: BaP, benz $[a]$ anthracene $(\mathrm{BaA})$, chrysene $(\mathrm{CHR})$, and benzo[b]fluoranthene $(\mathrm{BbFA})$ ) were set in Commission Regulation (EU) No. $835 / 2011$ [22]. The MLs for smoked meat and fish products smoked from 1.9.2012 to 31.8.2014 are $5.0 \mu \mathrm{g} \cdot \mathrm{kg}^{-1}$ for BaP and $30.0 \mu \mathrm{g} \cdot \mathrm{kg}^{-1}$ for the PAH4 sum. The MLs applicable from 1.9.2014 for smoked meat and fish products are $2.0 \mu \mathrm{g} \cdot \mathrm{kg}^{-1}$ for $\mathrm{BaP}$ and $12.0 \mu \mathrm{g} \cdot \mathrm{kg}^{-1}$ for the PAH4 sum [22]. However, in some Member States, the lower levels set from 1.9.2014 could not realistically be reached for traditionally smoked products. Therefore, Commission Regulation (EU) No. 1327/2014, amending Regulation (EC) No. 1881/2006, was set for three years, permitting certain Member States, including Finland, to produce and consume traditionally smoked meat and meat products, as well as fish and fish products, in their territory that comply with the PAH MLs of $5.0 \mu \mathrm{g} \cdot \mathrm{kg}^{-1}$ for BaP and $30.0 \mu \mathrm{g} \cdot \mathrm{kg}^{-1}$ for the PAH4 sum [23]. In this study, the PAH4 levels of Finnish smoked fish and meat products were determined. In addition, particular attention was paid to investigating the effect of selected smoking parameters on the PAH4 levels to develop science-based guidance for a safe smoking procedure. Particularly aimed at small and medium-sized enterprises (SMEs), guidance will strengthen their expertise and thereby prevent and reduce PAH contamination in traditionally smoked fish and meat products.

\section{Materials and Methods}

2.1. Samples. During 2012, the municipal food control authorities and the inspection veterinarians of the Finnish Food Safety Authority Evira collected 142 samples (80 fish/fishery products and 62 meat/meat products) throughout Finland from smokehouses and retail shops with their own smoking chambers. Among the meat and meat products, different types of pork products were the most common (68\%) (Figure 1(a)), and for the fish and fish products, either warm or cold smoked salmon products were predominant (82\%) (Figure 1(b)). Sampling was conducted according to Commission Regulation (EC) No. 333/2007 [24] and followed a risk-based sampling plan (e.g., the smoking technique used and production volumes). Only so-called worst-case samples from the consumer perspective, which were most likely to contain PAH compounds, were chosen for chemical analysis. Therefore, liquid-smoked samples, for instance, were not included. During the sampling, detailed information on the production process was recorded. However, incompletely reported smoking parameters were omitted.

2.2. Chemicals and Reagents. Organic solvents (dichloromethane, hexane, acetone, cyclohexane, methanol, and toluene) were HPLC or ultra resi-grade and purchased from J. T. Baker (Deventer, Netherlands). Ethyl acetate (HPLC grade) was obtained from VWR Chemicals (Fontenay-sousBois, France). Ethanol was provided by Altia Oyj (Rajamäki, Finland) and was of Aa grade ( $\geq 99.5 \%)$. Celite 545 and florisil (100-200 mesh) used for accelerated solvent extraction (ASE $200{ }^{\circledR}$, Dionex Corporation) were obtained from Merck (Darmstadt, Germany) and from Sigma-Aldrich (Steinheim, Germany), respectively. Supelclean ENVI-Chrom P (6 mL, $500 \mathrm{mg}$ ) solid-phase extraction cartridges were provided by Supelco (Bellefonte, PA, USA). The analytical standard mixture (PAH-Mix 183, $10 \mu \mathrm{g} \cdot \mathrm{mL}^{-1}$ ) was purchased from Dr. Ehrenstorfer GmbH (Augsburg, Germany). In addition, the isotopically labelled compounds (13C6 BaA, 13C6 CHR, 13C6 BbFA, and $13 \mathrm{C} 4 \mathrm{BaP}$ ) containing $100 \mu \mathrm{g} \cdot \mathrm{mL}^{-1}$ each were supplied by LGC Standards GmbH (Wesel, Germany) and used as internal standards. The stock solutions of the individual ${ }^{13} \mathrm{C}$ PAHs were prepared and combined in toluene. All the standard solutions were stored at $+4^{\circ} \mathrm{C}$, protected from the light.

2.3. Sample Preparation. PAH4 compounds were determined using a gas chromatography-tandem mass spectrometry (GC-MS/MS) method accredited according to ISO 17025. The method was based on the publication of Veyrand et al. [25], with minor modifications. All samples were packed in aluminium foil or in a sales package and stored at $+5^{\circ} \mathrm{C}$ prior to homogenisation in a food mixer. According to the manufacturer's information, the fish or meat skin was removed before homogenisation if the skin was not an edible part of the product. MLs are only applicable to the edible parts of smoked products. The samples were homogenised in a mixer, and approximately $100 \mathrm{~g}$ of each sample was taken to be freeze-dried. Half a gram of the dried sample was spiked with internal standards $\left({ }^{13} \mathrm{C}\right.$-labelled PAHs) followed by the extraction of PAHs using ASE $200{ }^{\circledR}$. The extraction cells were filled with celite and florisil and prewashed with dichloromethane before adding the sample and extracting 


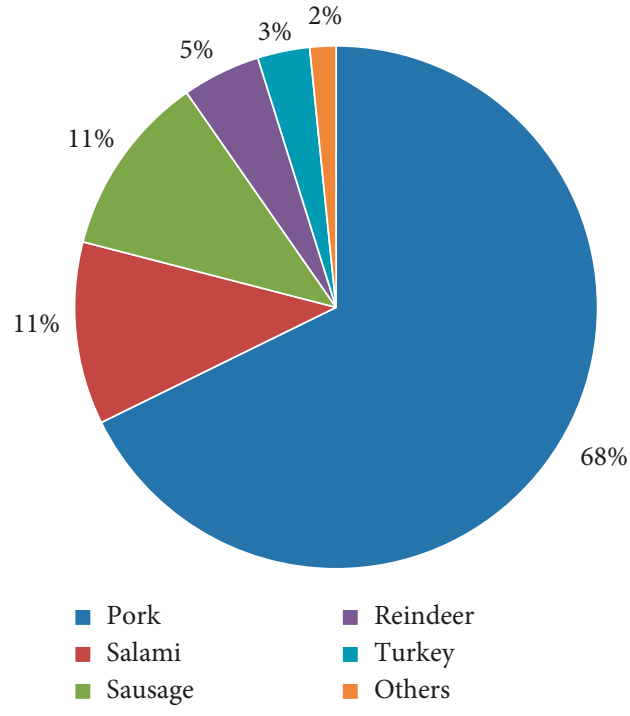

(a)

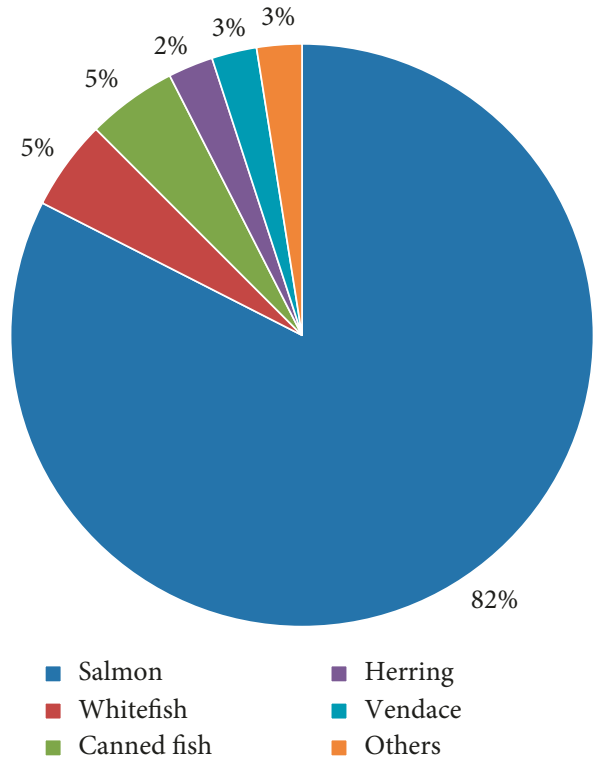

(b)

FIgURe 1: Percentage distribution of sampled (a) smoked meat $(n=62)$ and (b) fish $(n=80)$ products.

with hexane/acetone $(50 / 50, \mathrm{v} / \mathrm{v})$. The extract was evaporated, diluted into cyclohexane, and purified in the solidphase extraction (SPE) cartridge. The SPE cartridge was first conditioned (ethyl acetate, cyclohexane) and washed with cyclohexane/ethanol $(70 / 30, v / v)$, after which the sample extract was introduced into the SPE cartridge. The PAH compounds were eluted with cyclohexane/ethyl acetate $(40 / 60, v / v)$. Finally, the solvent was evaporated with nitrogen, and the sample was redissolved in $100 \mu \mathrm{l}$ toluene and transferred to a GC vial. For the GC-MS/MS analysis, one microliter of the final sample extract was injected into the GC injector. In the case of canned fish samples, the fish and oil were separated and analysed separately. The individual results were considered when calculating the final result for the canned fish product.

2.4. GC-MS/MS Analysis. The final detection and quantification of the analytes were performed using a gas chromatograph (Agilent, 6890N) coupled to a Micromass Quattro Micro GC triple quadrupole analyser (Waters, Micromass). Analysis was carried out using the Select PAH capillary column from Agilent J\&W $(30 \mathrm{~m} \times 0.25 \mathrm{~mm} \times 0.15 \mu \mathrm{m})$. Helium (AGA, Finland) was applied as the carrier gas at the constant flow rate of $1.0 \mathrm{~mL} \cdot \mathrm{min}^{-1}$ and argon (AGA, Finland) as the collision gas. The injection was done in splitless mode by utilising the electron ionisation (EI) technique $(70 \mathrm{eV})$. Ion transitions were monitored with the multiple reaction monitoring (MRM) mode, and the two most predominant fragments for each analyte were utilised. Precursor ions and the selected product ions are given in Table 1. The injector and the transfer line temperature were held at $300^{\circ} \mathrm{C}$ and the ion source at $275^{\circ} \mathrm{C}$. The GC oven temperature was initially kept at $110^{\circ} \mathrm{C}$ for $0.7 \mathrm{~min}$ and then raised at $5^{\circ} \mathrm{C} \cdot \mathrm{min}^{-1}$ to $180^{\circ} \mathrm{C}$, $3^{\circ} \mathrm{C} \cdot \mathrm{min}^{-1}$ to $230^{\circ} \mathrm{C}$ for $7 \mathrm{~min}, 28^{\circ} \mathrm{C} \cdot \mathrm{min}^{-1}$ to $280^{\circ} \mathrm{C}$ for
TABle 1: Precursor and product ions of PAH4 compounds.

\begin{tabular}{|c|c|}
\hline Compound and precursor ion $(\mathrm{m} / \mathrm{z})$ & Product ion $(\mathrm{m} / \mathrm{z})$ \\
\hline Benzo $[a]$ pyrene 252.3 & $226.2,250.1$ \\
\hline ISTD benzo $[a]$ pyrene ${ }^{13} \mathrm{C}_{4} 256.0$ & $254 . \overline{1}$ \\
\hline Benz[a] anthracene 228.2 & $202 . \overline{2,226.2}$ \\
\hline ISTD benz $[a]$ anthracene ${ }^{13} \mathrm{C}_{6} 234.0$ & 232.2 \\
\hline Chrysene 228.2 & $202.1, \underline{22} 6.1$ \\
\hline ISTD chrysene ${ }^{13} \mathrm{C}_{6} 234.0$ & 254.1 \\
\hline Benzo[b]fluoranthene 252.3 & $226.0,250.1$ \\
\hline ISTD benzo[ $b]$ fluoranthene ${ }^{13} \mathrm{C}_{6} 258.0$ & 256.2 \\
\hline
\end{tabular}

Underlined product ions are used as quantifier ions.

$15 \mathrm{~min}$, and $14^{\circ} \mathrm{C} \cdot \mathrm{min}^{-1}$ to $350^{\circ} \mathrm{C}$ for $5 \mathrm{~min}$. Quantification was performed by using the internal standard calibration curve with seven standards from 0 to $800 \mathrm{ng} \cdot \mathrm{mL}^{-1}$. The data were processed using MassLynx V4.1 software supplied by Waters (Manchester, United Kingdom).

2.5. Statistical Analysis. The statistical analysis was performed using IBM SPSS Statistics, version 25 (SPSS Inc., Chicago, Illinois). Boxplots were performed to visualise the distribution of the data sets.

2.6. Method Validation and Quality Control. The GC-MS/MS method complies with the criteria for the official control of PAH4 according to Commission Regulation (EU) No. $836 / 2011$ [26]. Method validation was performed for fish, meat, and oil matrices using Commission Decision (EC) No. 657/2002 as a guideline [1]. The following parameters were successfully tested: specificity, selectivity, linearity, repeatability, within-laboratory reproducibility, apparent recovery, the limit of detection (LOD), the limit of quantification (LOQ), and trueness. The proficiency test 
organised by FAPAS ${ }^{\circledR}$ was used to assess the trueness of the method. Smoked meat test material was analysed for $\mathrm{BaP}$, $\mathrm{BaA}$, and $\mathrm{BbFA}$, and our $z$-scores were $-0.7,0.1$, and -0.4 , respectively.

Quality controls of the method were performed both before and during the sample run. Each GC-MS/MS run was preceded by a system performance check with the standard solutions containing 0.011 and $0.064 \mu \mathrm{g} \cdot \mathrm{mL}^{-1}$ of PAH4 standards (PAH-Mix 183, Dr. Ehrenstorfer GmbH, Augsburg, Germany). In addition, the standard solutions were injected at the beginning, in the middle, and at the end of each sample batch. Individual internal standards were used for each PAH4 compound.

The spiked matrix sample was used to check the functionality of the whole method by spiking the blank fish or meat sample with PAH4 standards at the level of $5.0 \mu \mathrm{g} \cdot \mathrm{kg}^{-1}$ and analysing in each sample batch. The performance criteria set in Commission Regulation (EU) No. 836/2011 consider the recovery values $50-120 \%$, the $\mathrm{LOD} \leq 0.30 \mu \mathrm{g} \cdot \mathrm{kg}^{-1}$, and the $\mathrm{LOQ} \leq 0.90 \mu \mathrm{g} \cdot \mathrm{kg}^{-1}$ for each of the four substances acceptable [26]. All our performance values were within these limits. According to Commission Decision (EC) No. 657/2002 [1], the maximum permitted tolerances for relative ion intensities were defined during fish and meat validation and applied as an identification criteria (Table 2). A chromatographic peak which was eluting at the retention time of a target PAH was identified if qualifier ion was present and the ion ratio between quantifier and qualifier was within the acceptable ion ratio. As an example, benzo[a]pyrene in a meat sample with ion ratio of 5.3 is illustrated in Figure 2.

\section{Results}

The method used for the determination of PAH4 is routinely used and is accredited according to ISO 17025 [27]. The LOD and LOQ of the method were $0.26 \mu \mathrm{g} \cdot \mathrm{kg}^{-1}$ and $0.87 \mu \mathrm{g} \cdot \mathrm{kg}^{-1}$ for each PAH4 analyte in fish and meat, respectively. Upper bound concentrations were calculated, assuming that all values of the individual PAH4 compounds less than the LOQ were equal to the LOQ. Furthermore, the concentrations below the LOD were calculated as zero. Measurement uncertainty (MU) was based on the validation and proficiency test data [28]. Estimated as expanded uncertainty, MU varied from 16 to $27 \%$ in fish and from 10 to $22 \%$ in meat, depending on the PAH4 compound. For the PAH4 sum, MU was $44 \%$ in fish and $38 \%$ in meat.

In general, the determined PAH4 levels in smoked fish and meat samples were relatively low and below the prevailing MLs. Regarding the smoked fish products, the mean concentrations were $0.7 \mu \mathrm{g} \cdot \mathrm{kg}^{-1}$ for BaP and $3.9 \mu \mathrm{g} \cdot \mathrm{kg}^{-1}$ for the PAH4 sum. For smoked meat products, the mean BaP and PAH4 sum levels were $2.2 \mu \mathrm{g} \cdot \mathrm{kg}^{-1}$ and $11 \mu \mathrm{g} \cdot \mathrm{kg}^{-1}$, respectively. It is noteworthy, however, that our results displayed wide variation, particularly in meat products, for which the PAH4 sum concentrations ranged from not detected to $200 \mu \mathrm{g} \cdot \mathrm{kg}^{-1}$ (Table 3). Moreover, median $\mathrm{PAH}$ levels in pork products were higher than in other meat products.
TABLE 2: The calculated maximum permitted ion ratio tolerance for fish and meat samples.

\begin{tabular}{lcc}
\hline Compound & $\begin{array}{c}\text { Maximum permitted } \\
\text { ion ratio tolerance } \\
\text { for fish samples }\end{array}$ & $\begin{array}{c}\text { Maximum permitted } \\
\text { ion ratio tolerance } \\
\text { for meat samples }\end{array}$ \\
\hline Benzo $[a]$ pyrene & $4.0-7.5$ & $4.5-8.4$ \\
Benz $[a]$ anthracene & $4.0-6.6$ & $3.9-7.3$ \\
Chrysene & $3.6-5.9$ & $3.7-6.1$ \\
Benzo[b]fluoranthene & $6.2-12$ & $5.0-9.3$ \\
\hline
\end{tabular}

The smoked large fish products $(n=72)$ contained $79 \%$ fillets, $13 \%$ pieces, and $8 \%$ whole fish samples, whereas all eight small fish samples represented the whole fish. When comparing the data between the products of larger fish species (e.g., salmon and whitefish) and smaller fish (e.g., herring, vendace, and roach), those of smaller fish were found to contain higher median concentrations of PAHs (Table 3). The minimum and maximum values were approximately at the same level in both large and small fish species.

Within the framework of the study, four meat product samples were found noncompliant with the legislation, and in all these cases, direct smoking was used. The competent authorities enforced the operator of these products to modify the smoking process. After modifications, follow-up samples were taken to ensure the products were compliant with the legislation before allowing the placement of the products on the market.

Four canned smoked fish products were analysed, comprising either vendace or roach. The final results were calculated by combining the relative proportions of PAHs in the fish and vegetable oil in a can. In all of the cases, the PAH4 contamination was almost five times higher in the vegetable oil than in the fish part. A similar oil-fish $\mathrm{PAH}$ ratio (5:1) was reported by Lawrence and Weber [29] in canned smoked sardine. However, all the canned fish samples were compliant with the legislation.

\subsection{Effect of the Selected Smoking Parameters on the PAH4} Levels. The effect of the selected smoking parameters was studied using smoked fish and meat samples. Additionally, smoked salmon fillets $(n=57)$ were evaluated separately in order to eliminate the interfering factors, such as other fish species and effect of the skin. Salmon fillets were all smoked without the skin. Regarding the smoking time, more investigation in fish was needed; thus, cold and warm/hot smoked salmon fillets as well as large and small fish species were studied.

3.1.1. Smoking Technique. The samples were smoked using either a direct or an indirect smoking technique. In smoked fish samples, direct smoking technique produced only slightly higher $\mathrm{BaP}$ and $\mathrm{PAH} 4$ sum concentrations than indirect smoking. Exceptionally, one sample smoked with indirect technique contained highest PAH4 concentrations (Figure 3(a)). For smoked salmon fillets, the results 


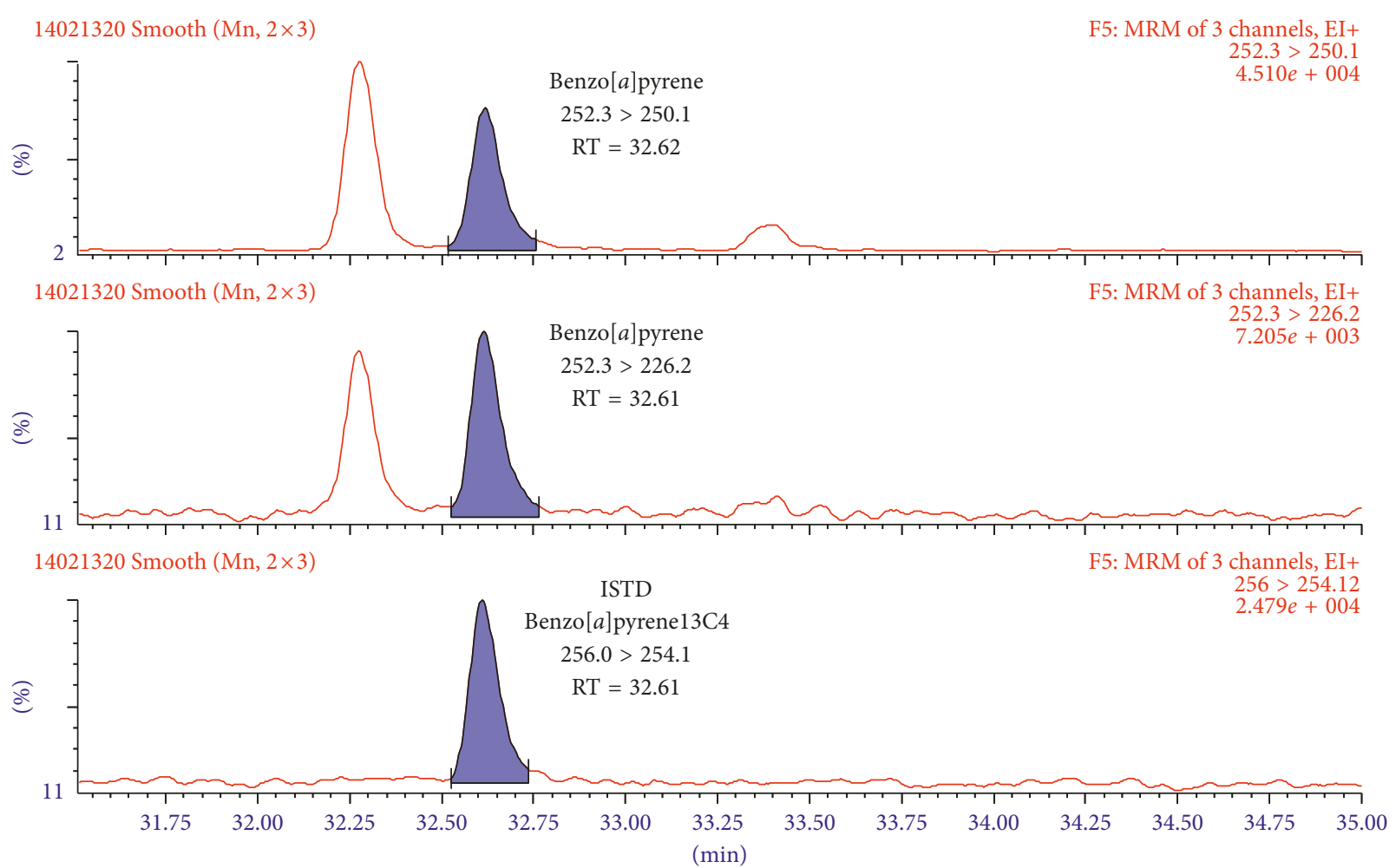

FIGURE 2: Multiple reaction monitoring chromatogram of benzo[a]pyrene at the level of $5.1 \mu \mathrm{g} \cdot \mathrm{kg}^{-1}$ in a meat sample.

TABLE 3: Median and minimum-maximum concentrations $\left(\mu \mathrm{g} \cdot \mathrm{kg}^{-1}\right)$ for BaP and PAH4 in products of large and small fish and in pork and other meat products.

\begin{tabular}{|c|c|c|c|c|}
\hline \multirow[b]{2}{*}{ Product type } & \multicolumn{2}{|c|}{$\mathrm{BaP}$} & \multicolumn{2}{|c|}{ PAH4 sum } \\
\hline & Median $\left(\mu \mathrm{g} \cdot \mathrm{kg}^{-1}\right)$ & $\begin{array}{c}\text { Minimum-maximum } \\
\left(\mu \mathrm{g} \cdot \mathrm{kg}^{-1}\right)\end{array}$ & Median $\left(\mu \mathrm{g} \cdot \mathrm{kg}^{-1}\right)$ & $\begin{array}{c}\text { Minimum-maximum } \\
\left(\mu \mathrm{g} \cdot \mathrm{kg}^{-1}\right)\end{array}$ \\
\hline Large fish products $(n=72)$ & 0 & $0-4.9$ & 0.3 & $0-26$ \\
\hline Small fish products $(n=8)$ & 0.9 & $0-3.8$ & 8 & $0-21$ \\
\hline Pork products $(n=42)$ & 0.8 & $0-40$ & 1.9 & $0-200$ \\
\hline Other meat products $(n=20)$ & 0 & $0-6.8$ & 0.4 & $0-38$ \\
\hline
\end{tabular}

illustrated direct smoking producing higher PAH levels than the indirect smoking (Figure 3(b)). Moreover, direct smoking generated clearly higher PAH levels in smoked meat samples than indirect smoking (Figure 3(c)).

3.1.2. Smoking Time. The effect of smoking time was examined by dividing the PAH results into two categories according to whether the smoking process took less or more than five hours. Surprisingly, the shorter smoking time generated higher PAH concentrations in fish samples, particularly observed for the PAH4 sum (Figures 4(a) and 4(b)). The comparison between cold smoked and warm or hot smoked salmon fillets indicated that in cold smoking process, only two samples contained detectable PAH concentrations (Figure 4(c)). In warm or hot smoked salmon fillets, which were mostly smoked in less than five hours, PAH levels were clearly higher than in cold smoked products. Moreover, the fish size may affect the observed PAH levels, which was studied between the large and small fish products. All the small fish products were smoked in less than five hours, and therefore, the comparison between the large and small fish products was performed in that time range. The results show the small fish samples containing higher median PAH levels (Figure 4(d)). In smoked meat samples, the $\mathrm{PAH}$ concentrations were higher for both $\mathrm{BaP}$ and the PAH4 sum when the smoking time exceeded five hours (Figure 4(e)).

3.1.3. Smoke Generation Temperature. The temperature required for smoke generation was defined as optimised if the thermal field was maintained at $400-600^{\circ} \mathrm{C}$ during the whole process. In a nonoptimised case, the temperature may vary during the process, and it is not therefore controlled. As expected, both for fish and meat samples, lower amounts of PAHs were formed when the temperature was optimised (Figures 5(a)-5(c)). Particularly, as shown in Figure 5(b), 


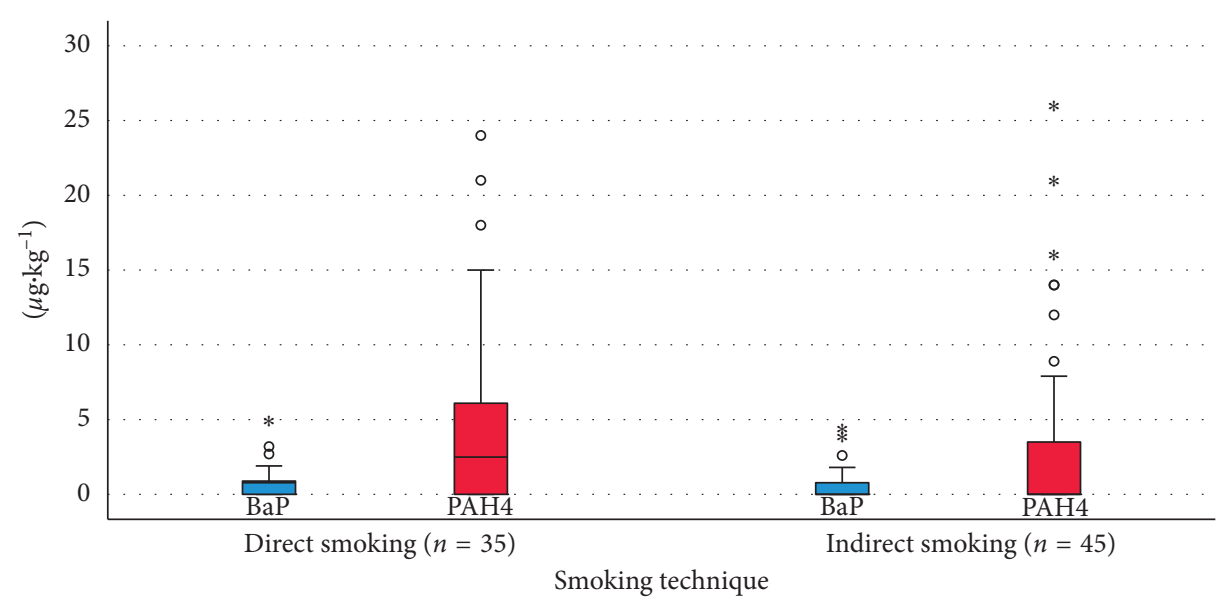

(a)

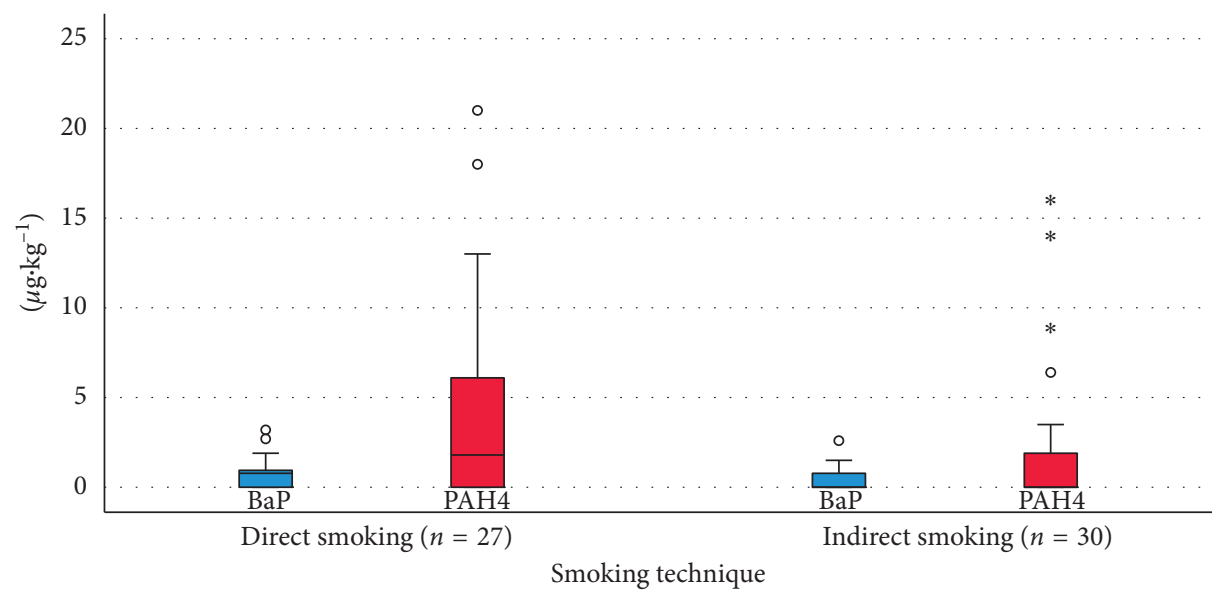

(b)

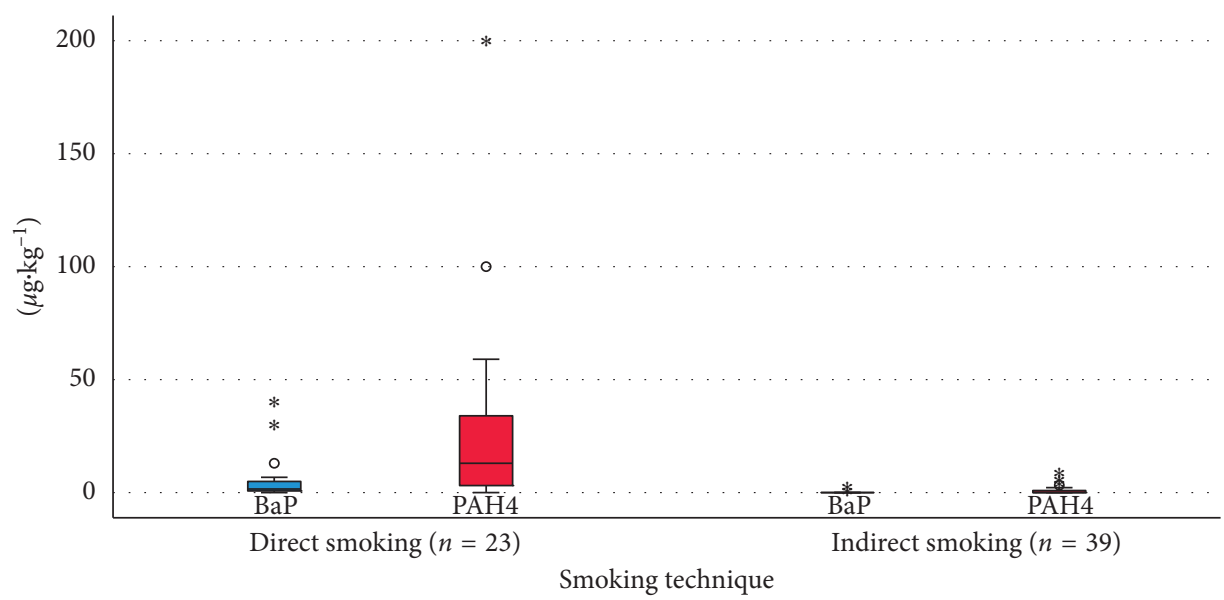

(c)

FIgURE 3: (a) Boxplot diagrams of $\mathrm{BaP}$ and PAH4 concentrations in $\mu \mathrm{g} \cdot \mathrm{kg}^{-1}$ wet weight for fish products divided according to the smoking technique used. The line in the central box represents the median, the whiskers show the distribution outside the central quartiles, and the circles and stars are outliers. $N$ is the number of samples. (b) Boxplot diagrams of BaP and PAH4 concentrations in $\mu \mathrm{g} \cdot \mathrm{kg}^{-1} \mathrm{wet}$ weight for salmon fillet products divided according to the smoking technique used. The line in the central box represents the median, the whiskers show the distribution outside the central quartiles, and the circles and stars are outliers. $N$ is the number of samples. (c) Boxplot diagrams of BaP and PAH4 concentrations in $\mu \mathrm{g} \cdot \mathrm{kg}^{-1}$ wet weight for meat products divided according to the smoking technique used. The line in the central box represents the median, the whiskers show the distribution outside the central quartiles, and the circles and stars are outliers. $N$ is the number of samples. 


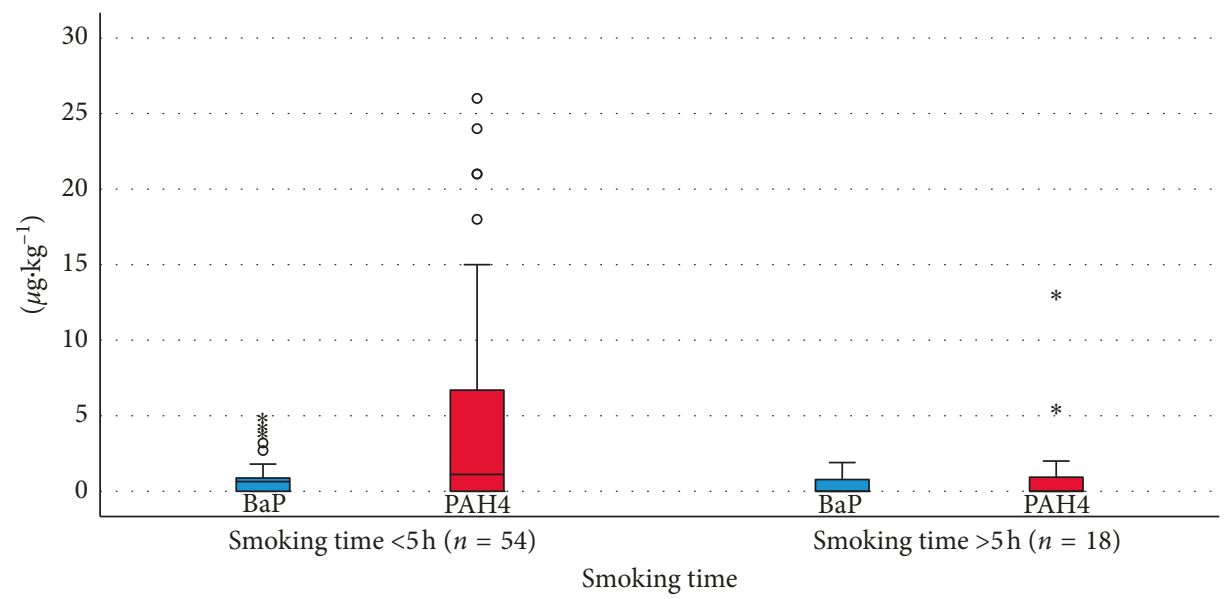

(a)

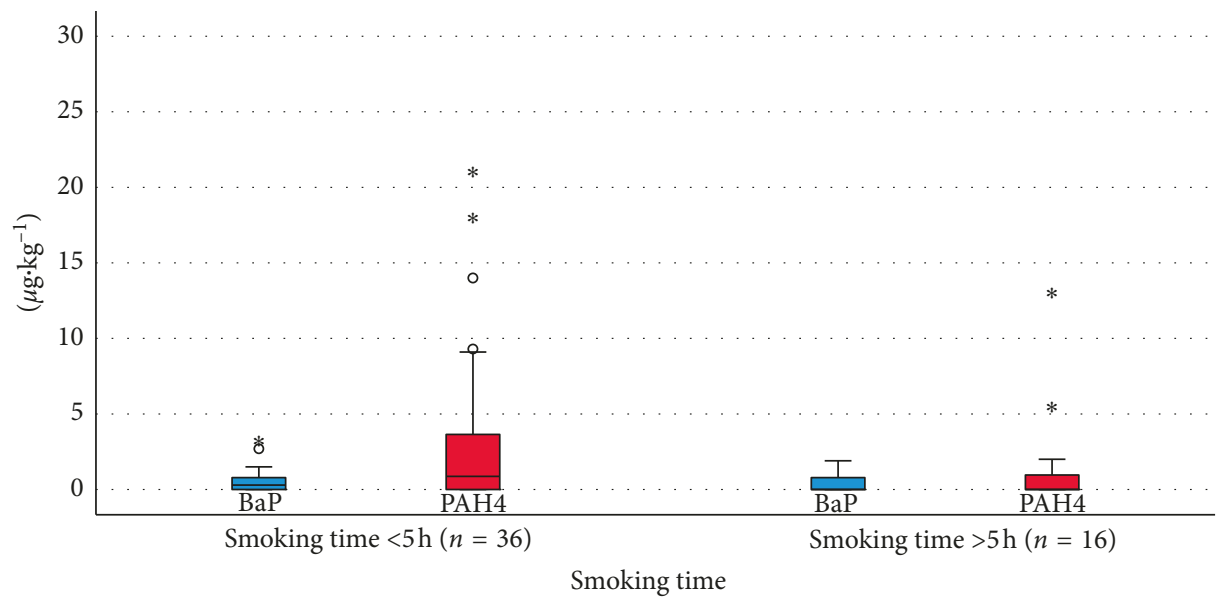

(b)

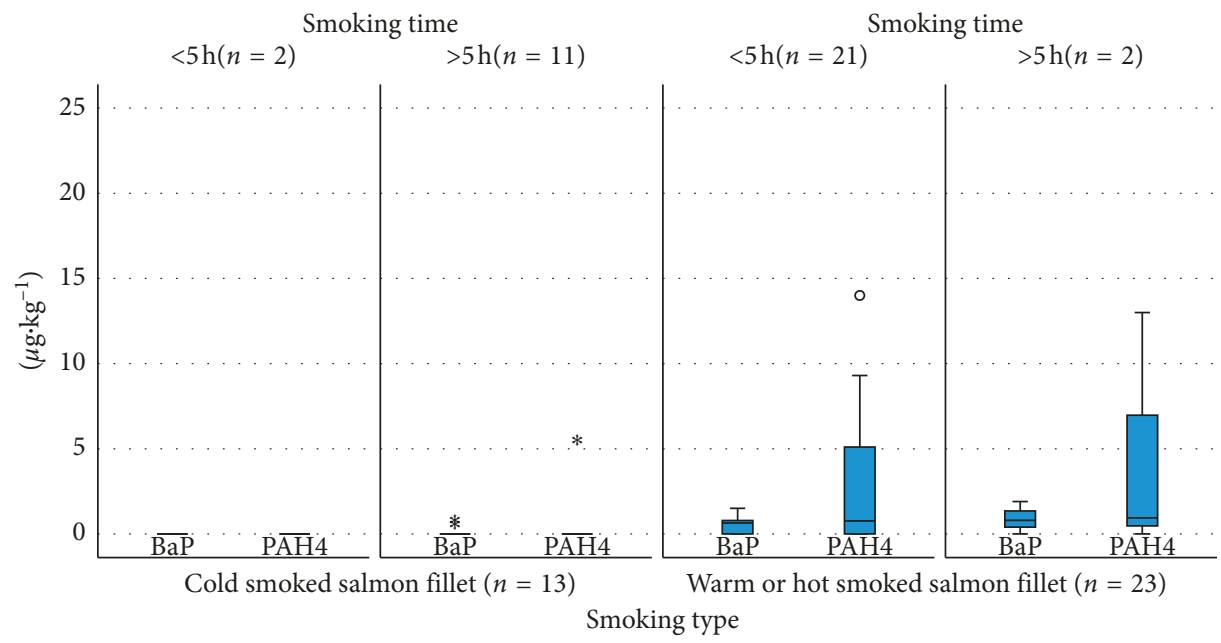

(c)

Figure 4: Continued. 


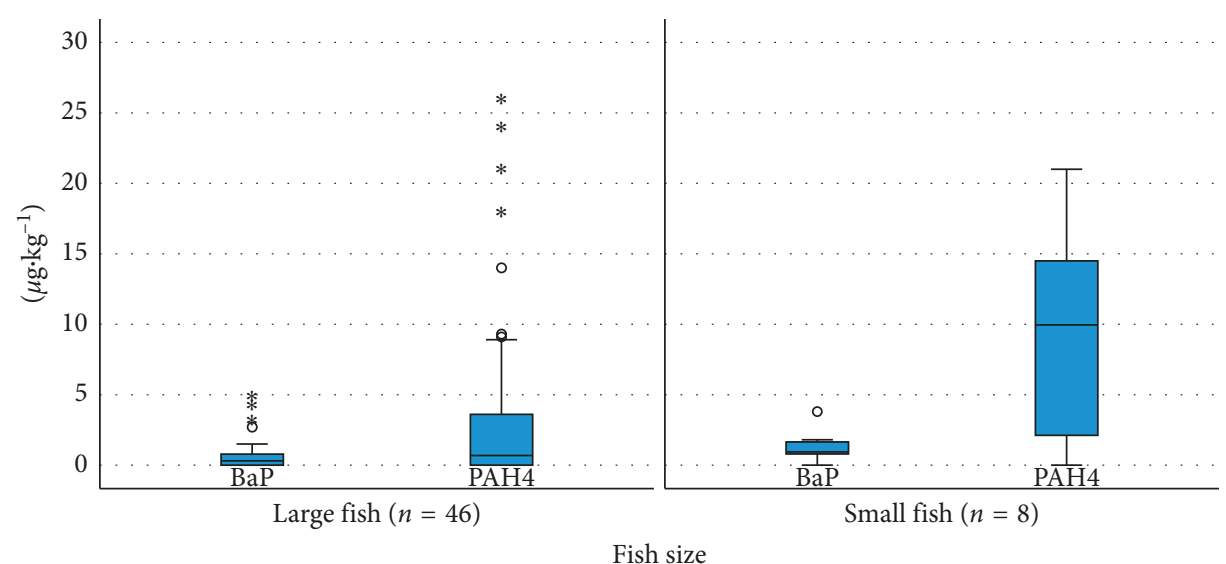

(d)

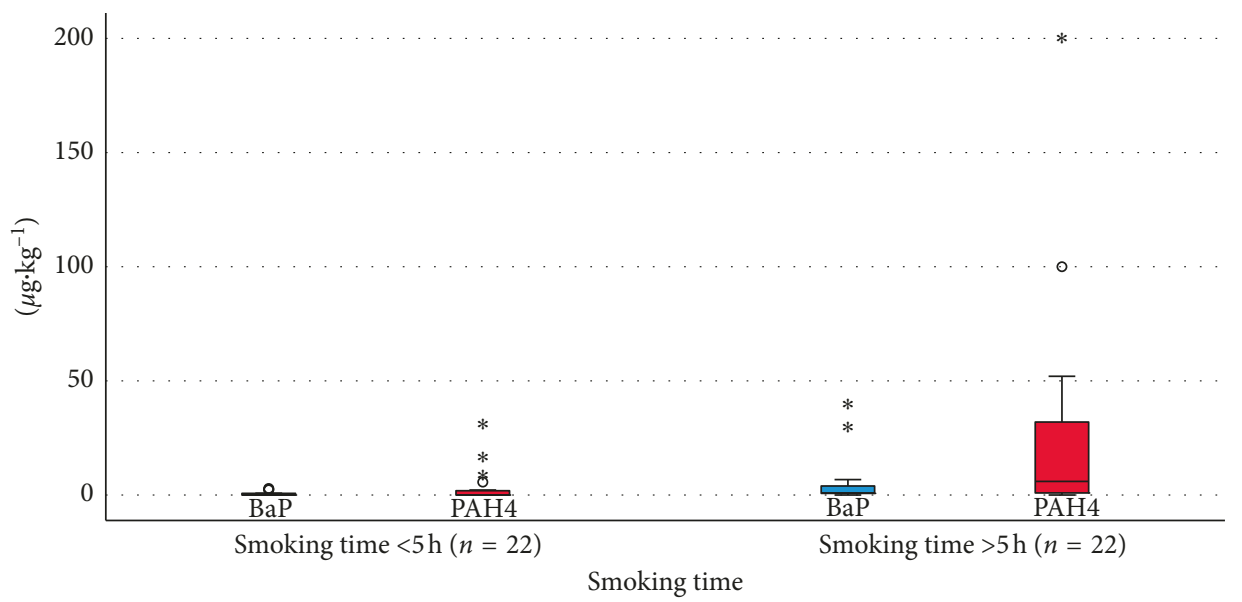

(e)

FIGURE 4: (a) Boxplot diagrams of BaP and PAH4 concentrations in $\mu \mathrm{g} \cdot \mathrm{kg}^{-1}$ wet weight for fish products divided according to the smoking time. The line in the central box represents the median, the whiskers show the distribution outside the central quartiles, and the circles and stars are outliers. $N$ is the number of samples. 72 samples contained the relevant information. (b) Boxplot diagrams of BaP and PAH4 concentrations in $\mu \mathrm{g} \cdot \mathrm{kg}^{-1}$ wet weight for salmon fillet products divided according to the smoking time. The line in the central box represents the median, the whiskers show the distribution outside the central quartiles, and the circles and stars are outliers. $N$ is the number of samples. 52 samples contained the relevant information. (c) Boxplot diagrams of BaP and PAH4 concentrations in $\mu \mathrm{g} \cdot \mathrm{kg}^{-1}$ wet weight for cold smoked and warm or hot smoked salmon fillets divided according to the smoking time. The line in the central box represents the median, the whiskers show the distribution outside the central quartiles, and the circles and stars are outliers. $N$ is the number of samples. 36 samples contained the relevant information. (d) Boxplot diagrams of $\mathrm{BaP}$ and PAH4 concentrations in $\mu \mathrm{g} \cdot \mathrm{kg}^{-1}$ wet weight for large and small fish products smoked in less than five hours. The line in the central box represents the median, the whiskers show the distribution outside the central quartiles, and the circles and stars are outliers. $N$ is the number of samples. 54 samples contained the relevant information. (e) Boxplot diagrams of $\mathrm{BaP}$ and $\mathrm{PAH} 4$ concentrations in $\mu \mathrm{g} \cdot \mathrm{kg}^{-1}$ wet weight for meat products divided according to the smoking time. The line in the central box represents the median, the whiskers show the distribution outside the central quartiles, and the circles and stars are outliers. $N$ is the number of samples. 44 samples contained the relevant information.

PAH levels were clearly higher for smoked salmon fillets in the nonoptimised system.

3.1.4. Distance between the Food and the Smoke Source. In this study, the reported length between the food and smoke source was either under or over five metres. The longer distance (over five metres) generated lower concentrations of PAHs in both fish and meat products (Figures 6(a)-6(c)). The comparison between PAH levels in smoked fish (Figure 6(a)) and salmon fillets (Figure 6(b)) demonstrated that similar results were obtained. Furthermore, there were no detectable levels of $\mathrm{BaP}$ in meat products when the distance from the smoke source was over five metres (Figure 6(c)).

\section{Discussion}

Food safety and especially the risk management of PAHs must be the first priority in food smoking processes, although smoking extends the food storage period and improves the flavour, composition, and preservation of the vitamin content [20]. The Codex Alimentarius recommends optimisation of the smoking process to produce smoked 


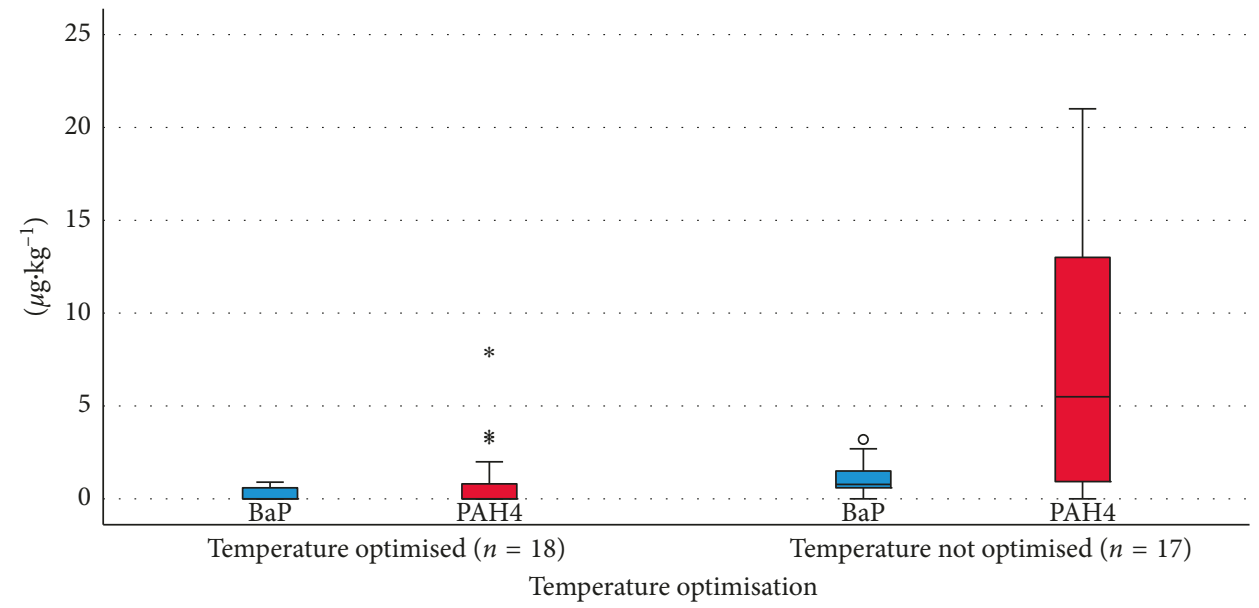

(a)

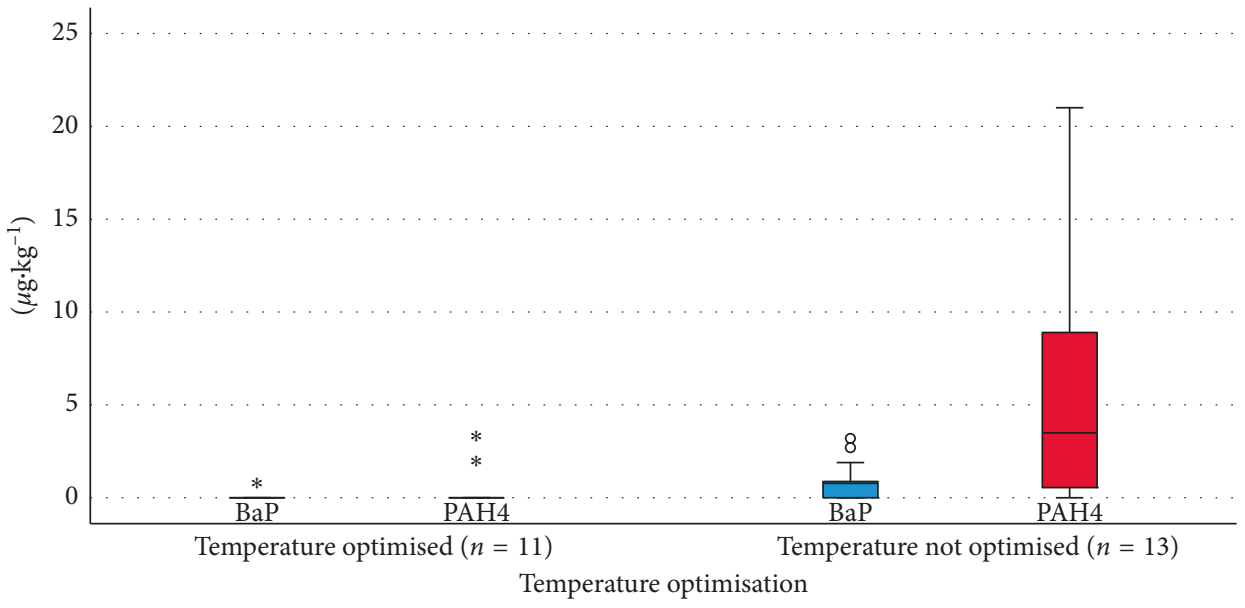

(b)

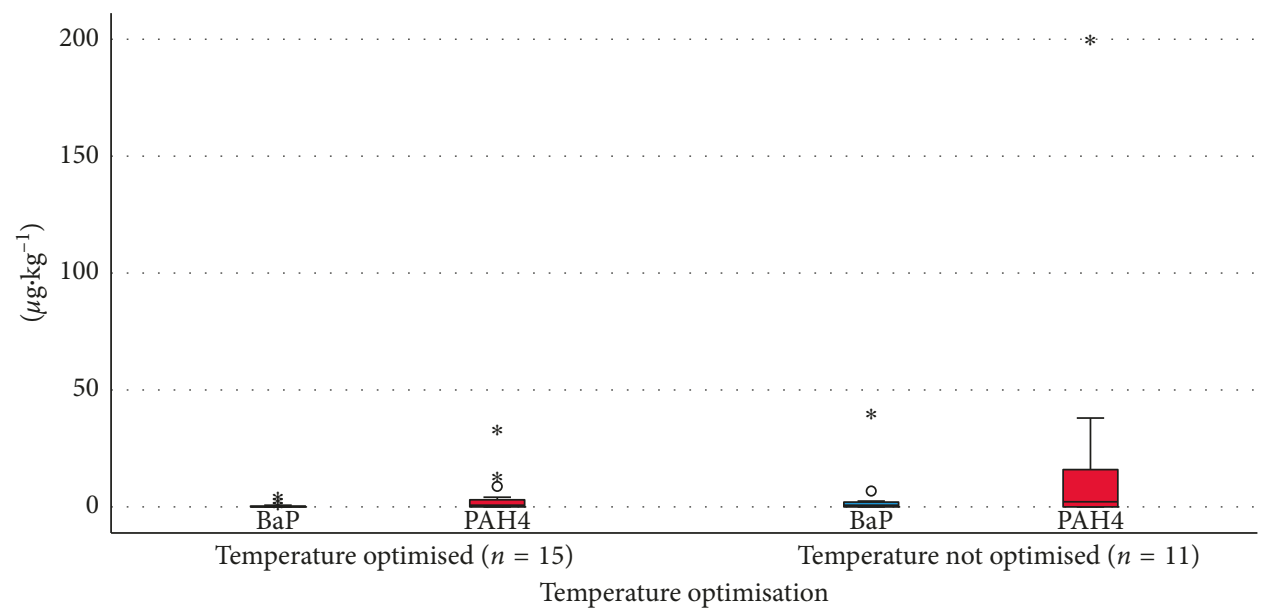

(c)

Figure 5: (a) Boxplot diagrams of $\mathrm{BaP}$ and PAH4 concentrations in $\mu \mathrm{g} \cdot \mathrm{kg}^{-1}$ wet weight for fish products divided according to the temperature optimisation. The line in the central box represents the median, the whiskers show the distribution outside the central quartiles, and the circles and stars are outliers. $N$ is the number of samples. 35 samples contained the relevant information. (b) Boxplot diagrams of $\mathrm{BaP}$ and $\mathrm{PAH} 4$ concentrations in $\mu \mathrm{g} \cdot \mathrm{kg}^{-1}$ wet weight for salmon fillet products divided according to the temperature optimisation. The line in the central box represents the median, the whiskers show the distribution outside the central quartiles, and the circles and stars are outliers. $N$ is the number of samples. 24 samples contained the relevant information. (c) Boxplot diagrams of BaP and PAH4 in $\mu \mathrm{g} \cdot \mathrm{kg}^{-1}$ wet weight for meat products divided according to the temperature optimisation. The line in the central box represents the median, the whiskers show the distribution outside, the central quartiles and the circles and stars are outliers. $N$ is the number of samples. 26 samples contained the relevant information. 


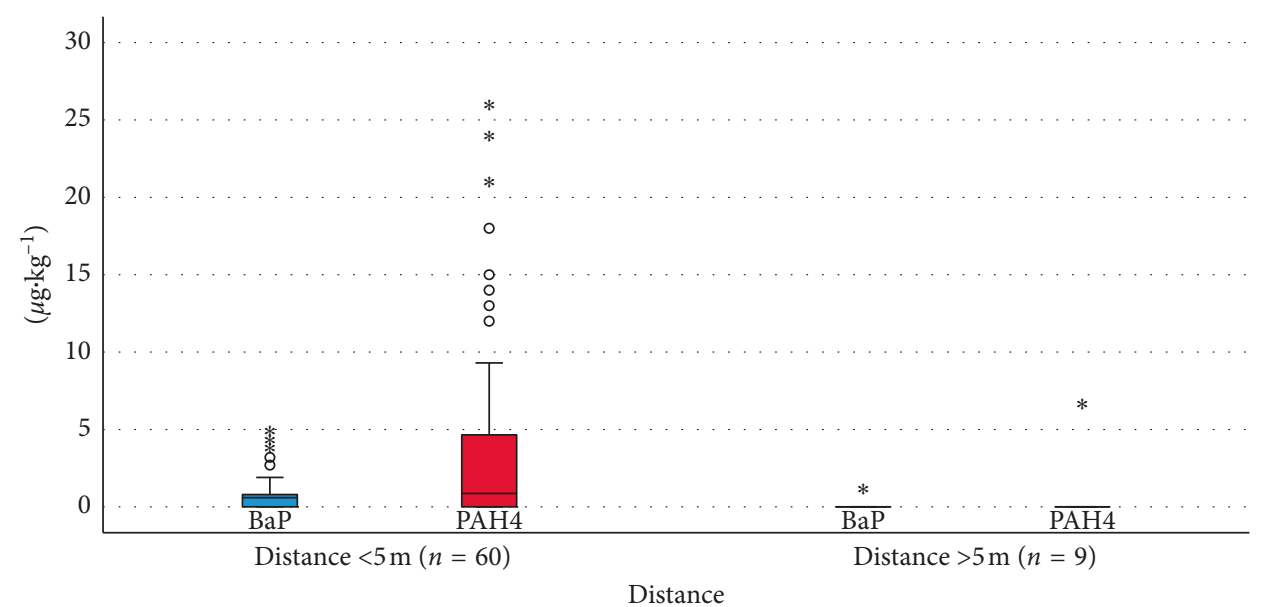

(a)

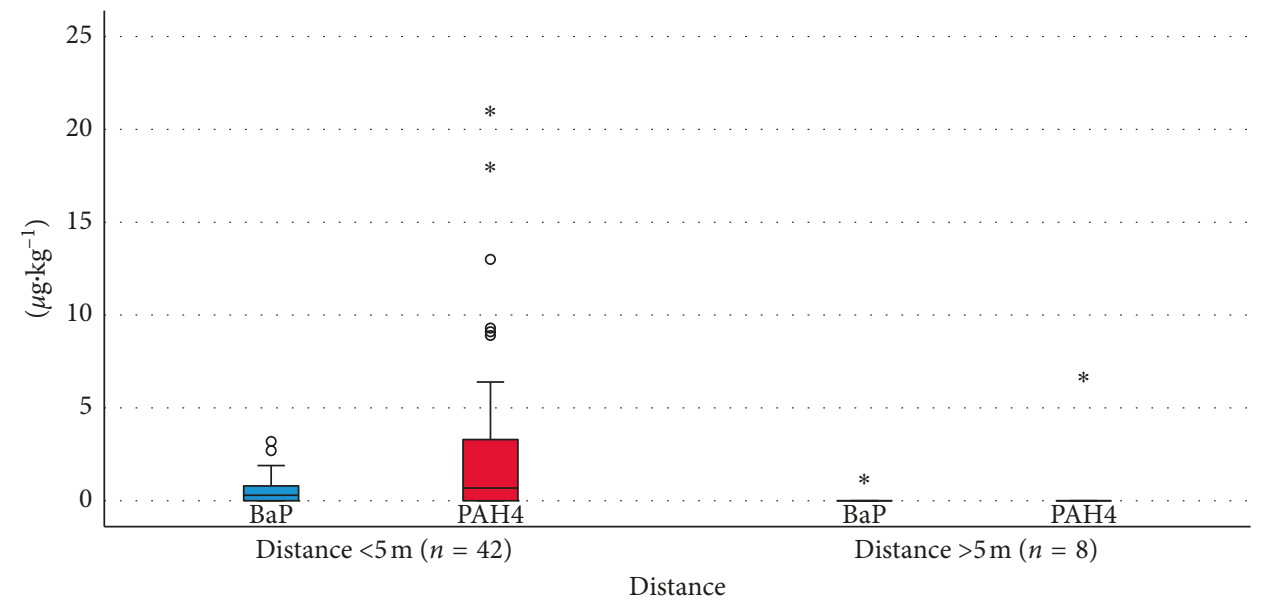

(b)

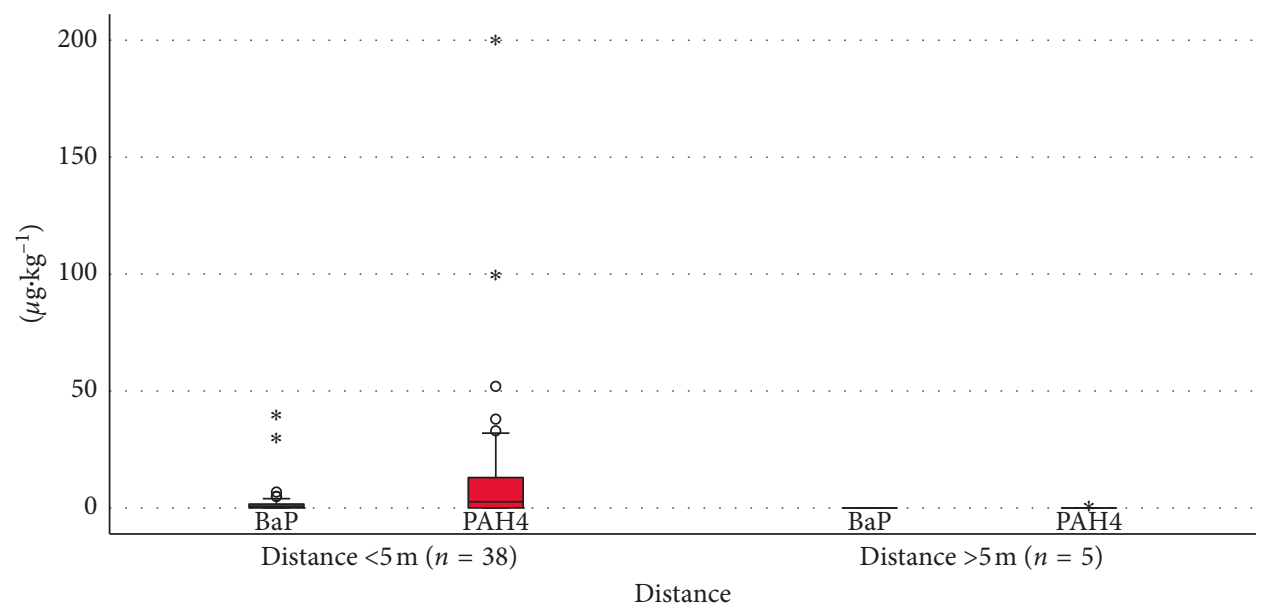

(c)

Figure 6: (a) Boxplot diagrams of BaP and PAH4 concentrations in $\mu \mathrm{g} \cdot \mathrm{kg}^{-1}$ wet weight for fish products divided according to the distance. The line in the central box represents the median, the whiskers show the distribution outside the central quartiles, and the circles and stars are outliers. $N$ is the number of samples. 69 samples contained the relevant information. (b) Boxplot diagrams of BaP and PAH4 concentrations in $\mu \mathrm{g} \cdot \mathrm{kg}^{-1}$ wet weight for salmon fillet products divided according to the distance. The line in the central box represents the median, the whiskers show the distribution outside the central quartiles, and the circles and stars are outliers. $N$ is the number of samples. 50 samples contained the relevant information. (c) Boxplot diagrams of BaP and PAH4 concentrations in $\mu \mathrm{g} \cdot \mathrm{kg}^{-1}$ wet weight for meat products divided according to the distance. The line in the central box represents the median, the whiskers show the distribution outside the central quartiles, and the circles and stars are outliers. $N$ is the number of samples. 43 samples contained the relevant information. 
products that have good microbiological quality and sensory properties with low PAH levels [20]. In order to control the PAH levels in smoked products, it is important to identify the critical parameters.

Overall, due to the risk-based, i.e., selective sampling in this study, the detected PAH4 levels in fish and meat were probably higher than would have been obtained using objective sampling. They were nevertheless relatively low and comparable to other studies $[18,30,31]$, with some exceptions. However, the large variation in PAH levels between the samples demonstrated how variable the smoking process can be in Finnish smokehouses. The smoking equipment used are rather self-made than commercial; thus, e.g., the length of smoking tube and the model of the filter may vary from one device to another. In 1999, the levels of 11 $\mathrm{PAHs}$ in different food categories were determined in Finland. Among smoked meat products, the highest $\mathrm{BaP}$ concentrations were observed in smoked pork products $\left(5.6-13.2 \mu \mathrm{g} \cdot \mathrm{kg}^{-1}\right)$, whereas in the smoked fish product category, a smoked herring sample contained a sum concentration of 11 PAHs of $270 \mu \mathrm{g} \cdot \mathrm{kg}^{-1}$, but a relatively low $\mathrm{BaP}$ concentration of $0.7 \mu \mathrm{g} \cdot \mathrm{kg}^{-1}$ [32]. Due to the different combinations of PAHs analysed, comparison with our results is challenging, but we observed the same trend of higher $\mathrm{PAH}$ levels in smoked pork products compared to other meat products. The data analysis did not reveal any particular smoking parameter alone to be the reason for the higher PAH levels in pork, but some factors were found related to long smoking time up to 36 hours, no distance between the food and smoke source or irregular cleaning of the smoking equipment. Altogether, the high variation among the results demonstrated the smoking process either to be controlled or not. Products of herring and also other small fish species such as vendace, roach, and mackerel contained higher PAH levels than those of larger fish species (salmon and whitefish). This may be attributed to the assumption that herring is often more heavily smoked than salmon due to the smaller surface area-to-volume ratio $[16,29]$.

Additionally, small fish species are consumed with the skin, which contains more PAHs than the other parts of the fish. According to previous studies [18, 33], the skin acts as a barrier to penetration by smoke particles, thereby preventing PAH contamination. The uptake of PAHs into the fish tissue is greater if the skin has been removed before smoking. When reaching the product surface, PAHs accumulate on the skin surface and may migrate into the underlying fatty tissue due to their solubility in fat. The water activity and fat content have a significant role in the diffusion process [15]. For smoked meat, similar conclusions were made by Ciecierska and Obiedziński [34], who demonstrated lower PAH levels in the interior than the exterior of the same products. In canned fish products, PAHs can migrate from the fish to the oil or remain in the fish lipid [35]. However, the oil mainly acts as a preservative, and many consumers pour away most of it before food consumption [35].

As expected, the smoking technique had a clear impact on the PAH levels. For both meat and fish products, direct smoking generated higher concentrations of $\mathrm{BaP}$ and $\mathrm{PAH} 4$ than indirect smoking. The European Commission reported in 2004 an average BaP concentration of $5.3 \mu \mathrm{g} \cdot \mathrm{kg}^{-1}$ for directly smoked fish, whereas for indirectly smoked fish, the $\mathrm{BaP}$ concentrations ranged from $0.1 \mu \mathrm{g} \cdot \mathrm{kg}^{-1}$ to $2.0 \mu \mathrm{g} \cdot \mathrm{kg}^{-1}$ [36]. The direct contact of the product with combustion gases is definitely an important source of PAH contamination $[3,6,15]$. In the direct smoking process, the combustion temperature is often very high and challenging to control $[16,18]$. The replacement of direct smoking by indirect smoking may reduce PAH contamination $[7,34]$. However, $100 \%$ of the directly smoked fish products and $82 \%$ of the directly smoked meat products were compliant with the legislation, so the direct technique is applicable when properly controlled. Similar findings were observed in Swedish meat and fish products that had been traditionally directly "sauna" smoked, in which the smoked meat products contained higher levels of $\mathrm{BaP}$ than the smoked fish products. The "sauna" smoking produced increased $\mathrm{BaP}$ levels in nine meat samples $\left(6.6-36.9 \mu \mathrm{g} \cdot \mathrm{kg}^{-1}\right)$ and in six fish samples $\left(8.4-14.4 \mu \mathrm{g} \cdot \mathrm{kg}^{-1}\right)$ [18].

The smoking time is one of the critical factors to consider in the smoking process, and it should be kept as short as possible, taking into account food safety and the product shelf life, because a prolonged smoking time increases the PAH exposure of the product $[19,20,37]$. This was especially noticeable in the meat sample results, whereas for fish samples, a shorter smoking time generated unexpectedly higher PAH concentrations than a longer smoking time. Fish results were divided into different groups to be able to evaluate them better. Similar findings were done in salmon fillets, which in turn were divided into cold smoked and warm or hot smoked fillets. The temperature differs generally from 12 to $25^{\circ} \mathrm{C}$ in cold smoking, from 25 to $45^{\circ} \mathrm{C}$ in warm smoking, and from 40 to $100^{\circ} \mathrm{C}$ in hot smoking [13]. Warm or hot smoking procedure generated more PAHs than the cold smoking, with some exceptions. Most of the cold smoked salmons (85\%) were smoked more than five hours, whereas $91 \%$ of the warm or hot smoked products were smoked less than five hours which explains the higher PAH levels in salmon fillets within shorter smoking time. The results are in agreement with Danish studies, which indicated hot smoking producing higher PAH levels than cold smoking [16]. Moreover, all the small fish species, such as herring and vendace, were smoked in less than five hours with higher median PAH levels compared to larger fish species (e.g., salmon and whitefish). A smaller product size may result in the formation of higher PAH levels [16].

The most significant parameter influencing the PAH concentrations in smoked products is the smoke generation temperature [13]. The composition of smoke is dependent on the temperature, which needs to be regulated to reduce the formation of PAHs [20]. According to Göbel [37], PAHs easily form in the temperature range between 660 and $740^{\circ} \mathrm{C}$. When temperature is increased within the range $400-1000^{\circ} \mathrm{C}$, there is a linear increase in the formation of PAHs in smoke $[18,38]$. Based on our results, smaller amounts of PAHs were formed when the smoke generation temperature was optimised to 
$400-600^{\circ} \mathrm{C}$ than in nonoptimised conditions. The difference in $\mathrm{PAH}$ levels between the optimised and nonoptimised processes was obvious in both fish and meat samples, which emphasises the significance of temperature optimisation. Typically, the smoke generation temperature varies between 500 and $800^{\circ} \mathrm{C}$ and is controlled by the air supply [33].

Besides the temperature, the distance between the food and the smoke source is among the important factors to observe. PAHs are bound to smoke particles, and a longer distance from the smoke source to the smoked food may therefore lead to lower PAH levels in the food [20]. The analysed fish and meat samples smoked at a distance over five metres from the smoke source contained lower levels of PAHs. In indirect smoking, the length of the smoking tube varied between 0.2 and 23 metres. Naturally, all the samples smoked with the direct technique were placed in the same chamber as the smoke source, and the distance was therefore always under five metres. It can be expected that PAH levels will then be higher, because, as previously mentioned, direct smoking leads to higher concentrations of PAHs in the products. To be able to reduce the PAH levels in the final product, an external smoke generator combined with a long tube could be a good option.

Evaluating the significance of smoked meat and fish in the average diets of several European countries, the Scientific Committee on Food (SCF) estimated the intake of BaP from smoked fish and meat to form only a small part of the total dietary intake [13]. However, in local communities or in certain countries, e.g., in Finland or Sweden [18], where smoked fish and meat traditionally constitute a significant proportion of the diet, the intake of $\mathrm{BaP}$ and other PAH4 compounds from these sources is significantly higher [13]. Regarding the European Commission's estimation in 2004, the average BaP intake in Finland is up to $270 \mathrm{ng} /$ person/day, whereas elsewhere in Europe, the intake varies between 14 and $320 \mathrm{ng} /$ person/day [36]. The Codex Alimentarius code of practice advises that in smoking, attention should be paid to choosing wood with a low lignin content, filtering or cooling the smoke, replacing direct with indirect smoking when possible, optimising the smoking time, temperature, and airflow, avoiding fat dripping onto the heat source, regularly cleaning and maintaining the equipment, increasing the distance of the product from the smoking source, and washing the product with water after smoking [20]. In order to precisely determine the influence of the smoking method and other processing parameters on the $\mathrm{PAH}$ contamination of food, the Codex Alimentarius and EU regulators require further scientific information [20].

\section{Conclusions}

Based on our results to obtain safe fish and meat products regarding $\mathrm{PAHs}$ in traditional smoking, indirect smoking with distance more than five meters between food and smoke source as well as smoking time less than five hours and an optimised temperature (without jeopardising microbiological food safety) are recommended.

\section{Data Availability}

The data used to support the findings of this study are available from the corresponding author upon request.

\section{Conflicts of Interest}

The authors declare that there are no conflicts of interest regarding the publication of this paper.

\section{Acknowledgments}

We are very grateful for the sampling performed by the municipal food control authorities and the inspection veterinarians of Evira. We thank Kristian Alho for performing the PAH analysis and Dr. Jukka Ranta for the statistical advice. In addition, we would like to thank the whole sample pretreatment team.

\section{References}

[1] Commission of the European Communities, "Commission decision of 12 August 2002 implementing Council Directive 96/23/EC concerning the performance of analytical methods and the interpretation of results," Official Journal of the European Union, vol. L221, pp. 8-36, 2002.

[2] P. Šimko, "Determination of polycyclic aromatic hydrocarbons in smoked meat products and smoke flavouring food additives," Journal of Chromatography B, vol. 770, no. 1-2, pp. 3-18, 2002.

[3] European Food Safety Authority, "Polycyclic aromatic hydrocarbons in food. Scientific opinion of the panel on contaminants in the food chain adopted on 9 June 2008," EFSA Journal, vol. 724, pp. 1-114, 2008.

[4] M.-K. Song, M. Song, H.-S. Choi, Y.-J. Kim, Y.-K. Park, and J.-C. Ryu, "Identification of molecular signatures predicting the carcinogenicity of polycyclic aromatic hydrocarbons (PAHs)," Toxicology Letters, vol. 212, no. 1, pp. 18-28, 2012.

[5] International Agency for Research on Cancer, "Chemical agents and related occupations. A review of human carcinogens. IARC Monographs on the evaluation of carcinogenic risks to humans," December 2016, https://monographs.iarc.fr/ wp-content/uploads/2018/06/mono100F.pdf.

[6] G. Purcaro, S. Moret, and L. S. Conte, "Overview on polycyclic aromatic hydrocarbons: occurrence, legislation and innovative determination in foods," Talanta, vol. 105, pp. 292-305, 2013.

[7] Scientific Committee on Food, "Opinion of the Scientific Committee on Food on the risks to human health of polycyclic aromatic hydrocarbons in food, expressed on 4 December 2002," Report No. SCF/CS/CNTM/PAH/29 Final, Scientific Committee on Food, Brussels, Belgium, October 2016, https://ec.europa.eu/food/sites/food/files/safety/docs/ sci-com_scf_out153_en.pdf.

[8] World Health Organization, "Evaluation of certain food additives and contaminants in WHO food additive report series," vol. 28, October 2016, http://www.inchem.org/ documents/jecfa/jecmono/v28je18.htm.

[9] M. Rose, J. Holland, A. Dowding et al., "Investigation into the formation of PAHs in foods prepared in the home to determine the effects of frying, grilling, barbecuing, toasting and roasting," Food and Chemical Toxicology, vol. 78, pp. 1-9, 2015. 
[10] V. Bansal and K. Kim, "Review of PAH contamination in food products and their health hazards," Environment International, vol. 84, pp. 26-38, 2015.

[11] E. Ledesma, M. Rendueles, and M. Díaz, "Spanish smoked meat products: benzo(a)pyrene $(\mathrm{BaP})$ contamination and moisture," Journal of Food Composition and Analysis, vol. 37, pp. 87-94, 2015.

[12] J. M. Lingbeck, P. Cordero, C. A. O'Bryan, M. G. Johnson, S. C. Ricke, and P. G. Crandall, "Functionality of liquid smoke as an all-natural antimicrobial in food preservation," Meat Science, vol. 97, no. 2, pp. 197-206, 2014.

[13] A. Stołyhwo and Z. E. Sikorski, "Polycyclic aromatic hydrocarbons in smoked fish-a critical review," Food Chemistry, vol. 91, no. 2, pp. 303-311, 2005.

[14] A. Theobald, D. Arcella, A. Carere et al., "Safety assessment of smoke flavouring primary products by the European Food Safety Authority," Trends in Food Science \& Technology, vol. 27, no. 2, pp. 97-108, 2012.

[15] E. Fasano, I. Yebra-Pimentel, E. Martínez-Carballo, and J Simal-Gándara, "Profiling, distribution and levels of carcinogenic polycyclic aromatic hydrocarbons in traditional smoked plant and animal foods," Food Control, vol. 59, pp. 581-590, 2016.

[16] L. Duedahl-Olesen, J. H. Christensen, A. Højgård, K. Granby, and M. Timm-Heinrich, "Influence of smoking parameters on the concentration of polycyclic aromatic hydrocarbons (PAHs) in Danish smoked fish," Food Additives \& Contaminants: Part A, vol. 27, no. 9, pp. 1294-1305, 2010.

[17] P. Visciano, M. Perugini, F. Conte, and M. Amorena, "Polycyclic aromatic hydrocarbons in farmed rainbow trout (Oncorhynchus mykiss) processed by traditional flue gas smoking and by liquid smoke flavourings," Food and Chemical Toxicology, vol. 46, no. 5, pp. 1409-1413, 2008.

[18] S. Wretling, A. Eriksson, G. A. Eskhult, and B. Larsson, "Polycyclic aromatic hydrocarbons (PAHs) in Swedish smoked meat and fish," Journal of Food Composition and Analysis, vol. 23, no. 3, pp. 264-272, 2010.

[19] D. K. Essumang, D. K. Dodoo, and J. K. Adjei, "Effect of smoke generation sources and smoke curing duration on the levels of polycyclic aromatic hydrocarbon (PAH) in different suites of fish," Food and Chemical Toxicology, vol. 58, pp. 86-94, 2013.

[20] Codex Alimentarius Commission, "Code of practice for the reduction of contamination of food with polycyclic aromatic hydrocarbons (PAH) from smoking and direct drying processes, CAC/RCP," vol. 68, July 2017, http:// www.codexalimentarius.org/download/standards/11257/ CXP_068e.pdf.

[21] Commission of the European Communities, "Commission regulation (EC) no. 1881/2006 of 19 December 2006 setting maximum levels for certain contaminants in foodstuffs," Official Journal of the European Union, vol. L364, pp. 5-24, 2006.

[22] European Commission, "Commission regulation (EU) no 835/2011 of 19 August 2011 amending regulation (EC) no $1881 / 2006$ as regards maximum levels for polycyclic aromatic hydrocarbons in foodstuffs," Official Journal of the European Union, vol. L215, pp. 4-8, 2011.

[23] European Commission, "Commission regulation (EU) no $1327 / 2014$ of 12 December 2014 amending regulation (EC) no 1881/2006 as regards maximum levels of polycyclic aromatic hydrocarbons (PAHs) in traditionally smoked meat and meat products and traditionally smoked fish and fishery products," Official Journal of the European Union, vol. L358, pp. 13-14, 2014.
[24] Commission of the European Communities, "Commission regulation (EC) no 333/2007 of 28 March 2007 laying down the methods of sampling and analysis for the official control of the levels of lead, cadmium, mercury, inorganic tin, 3-MCPD and benzo(a)pyrene in foodstuffs," Official Journal of the European Union, vol. L88, pp. 29-38, 2007.

[25] B. Veyrand, A. Brosseaud, L. Sarcher et al., "Innovative method for determination of 19 polycyclic aromatic hydrocarbons in food and oil samples using gas chromatography coupled to tandem mass spectrometry based on an isotope dilution approach," Journal of Chromatography A, vol. 1149, no. 2, pp. 333-344, 2007.

[26] The European Commission, "Commission regulation (EU) no 836/2011 of 19 August 2011 amending regulation (EC) no 333/ 2007 laying down the methods of sampling and analysis for the official control of the levels of lead, cadmium, mercury, inorganic tin, 3-MCPD and benzo(a)pyrene in foodstuffs," Official Journal of the European Union, vol. L215, pp. 9-16, 2011.

[27] International Organisation for Standardization, "General requirements for the competence of testing and calibration laboratories, ISO/IEC 17025: 2005," July 2018, http://www.iso. org/iso/home.htm.

[28] Nordic Committee on Food Analysis, Procedure No. 5: Estimation and Expression of Measurement Uncertainty in Chemical Analysis, Nordic Committee on Food Analysis, Oslo, Norway, 2003.

[29] J. F. Lawrence and D. F. Weber, "Determination of polycyclic aromatic hydrocarbons in some Canadian commercial fish, shellfish, and meat products by liquid chromatography with confirmation by capillary gas chromatography-mass spectrometry," Journal of Agricultural and Food Chemistry, vol. 32, pp. 789-794, 1984.

[30] L. Duedahl-Olesen, S. White, and M. L. Binderup, "Polycyclic aromatic hydrocarbons (PAH) in Danish smoked fish and meat products," Polycyclic Aromatic Compounds, vol. 26, no. 3, pp. 163-184, 2006.

[31] M. Reinik, T. Tamme, M. Roasto, K. Juhkam, T. Tenno, and A. Kiis, "Polycyclic aromatic hydrocarbons (PAHs) in meat products and estimated $\mathrm{PAH}$ intake by children and the general population in Estonia," Food Additives and Contaminants, vol. 24, no. 4, pp. 429-437, 2007.

[32] V. Hietaniemi, M. Ovaskainen, and A. Hallikainen, "PAH-yhdisteet ja niiden saanti markkinoilla olevista elintarvikkeista," Elintarvikevirasto Survey, vol. 6, pp. 1-27, 1999, in Finnish.

[33] M. Pöhlmann, A. Hitzel, F. Schwägele, K. Speer, and W. Jira, "Influence of different smoke generation methods on the contents of polycyclic aromatic hydrocarbons (PAH) and phenolic substances in Frankfurter-type sausages," Food Control, vol. 34, no. 2, pp. 347-355, 2013.

[34] M. Ciecierska and M. Obiedziński, "Influence of smoking process on polycyclic aromatic hydrocarbons' content in meat products," Acta Scientiarum Polonorum Technologia Alimentaria, vol. 6, pp. 17-28, 2007.

[35] S. Moret, G. Purcaro, and L. S. Conte, "Polycyclic aromatic hydrocarbons in vegetable oils from canned foods," European Journal of Lipid Science and Technology, vol. 107, no. 7-8, pp. 488-496, 2005.

[36] Directorate-General Health and Consumer Protection, "Collection of occurrence data on polycyclic aromatic hydrocarbons in food," in Reports on Tasks for Scientific Cooperation. Report of Experts Participating in Task 3.2.12. October 2004, pp. 1-36, EFSA Publication, Parma, Italy, 2004. 
[37] A. Göbel, "Sachstandsbericht: polycyclische aromatische kohlenwasserstoffe (PAH)-ermittlung von herstellungs- und verarbeitungsverfahren mit dem ziel der reduzierung and vermeidung von PAH in lebensmitteln," Journal für Verbraucherschutz und Lebensmittelsicherheit, vol. 1, no. 4, pp. 271-284, 2006, in German.

[38] M. Jägerstad and K. Skog, "Genotoxicity of heat-processed foods," Mutation Research/Fundamental and Molecular Mechanisms of Mutagenesis, vol. 574, no. 1-2, pp. 156-172, 2005. 

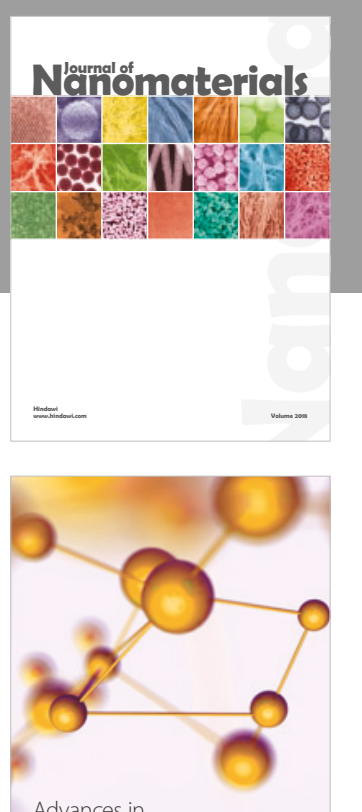

Physical Chemistry
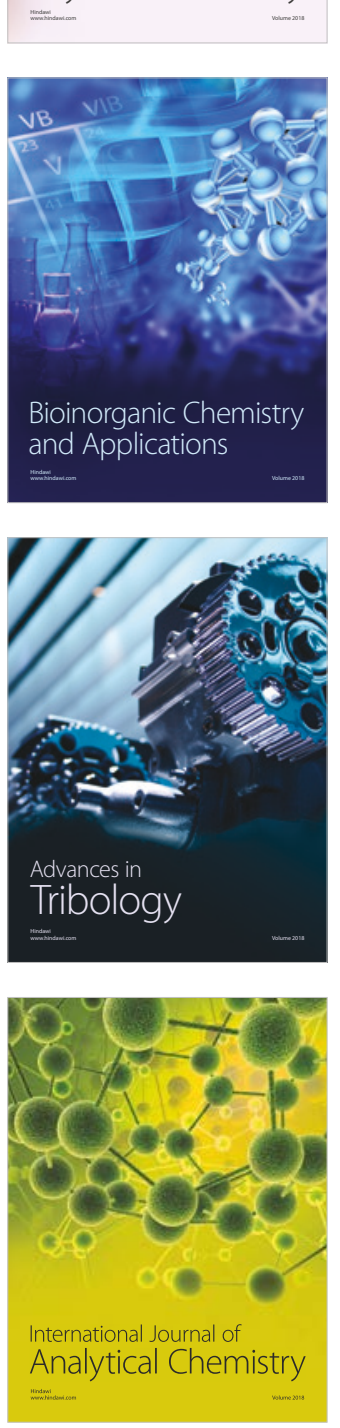

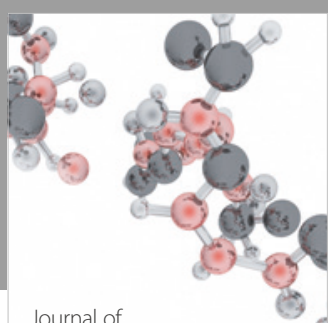

Analytical Methods

in Chemistry

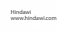

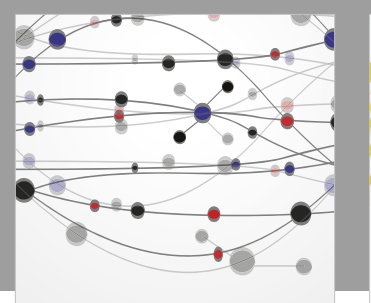

The Scientific World Journal

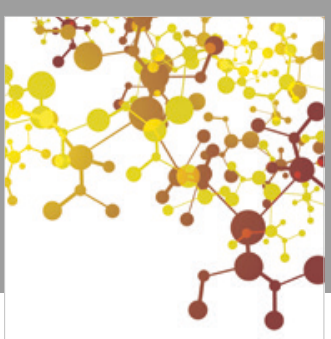

Journal of

Applied Chemistry
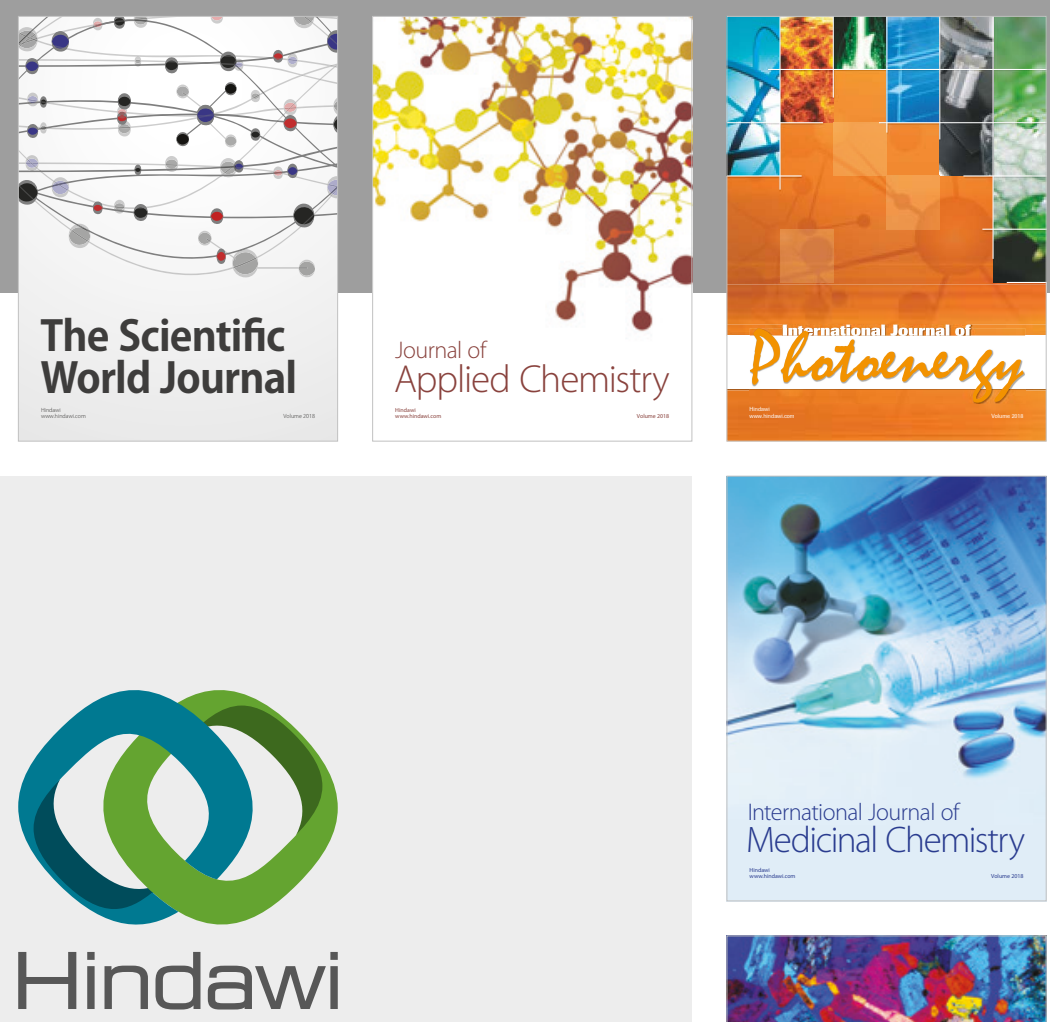

Submit your manuscripts at

www.hindawi.com
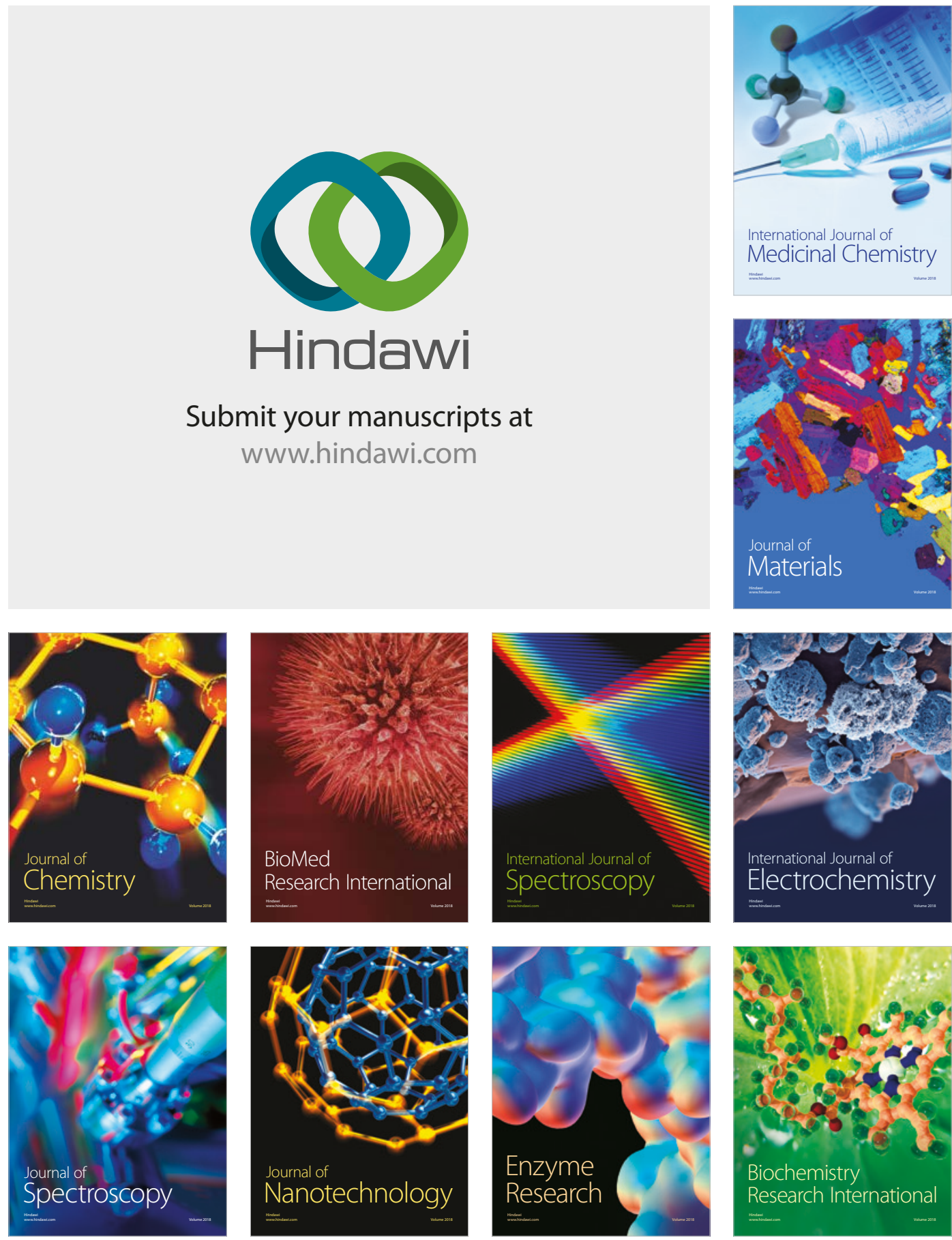
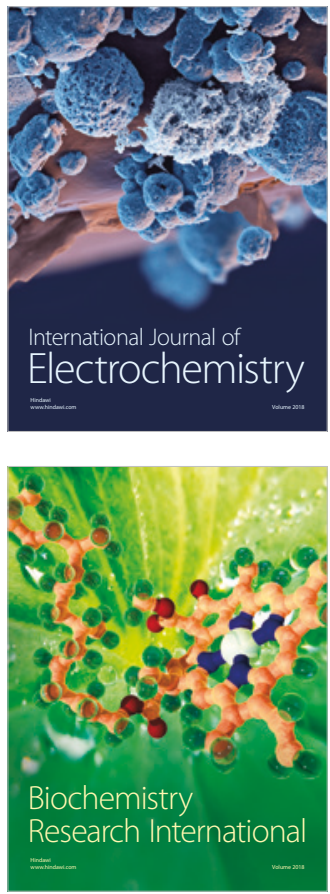